\title{
Resultados clínicos e funcionais da cirurgia de reconstrução do LCA contralateral em médio prazo
}

\section{Clinical results and functional surgery the $A C L$ reconstruction contralateral in medium}

term

\section{Gabriela Ataides ${ }^{1}$ Márcio Oliveira ${ }^{2}$ Paulo Lobo Júnior ${ }^{3}$ Rayane de Araújo ${ }^{4}$ Paulo Henrique 5 Révia Lima ${ }^{6}$ Meire Damado ${ }^{7}$}

Recebido em: 04/07/2012

Aprovado em: 04/05/2013

1 Fisioterapeuta. E-mail: gabiataides@hotmail. com

2 Especialista em Fisioterapia Traumato-Ortopédica Funcional e Esportiva (UCB/RJ); Mestre em Ciências da Saúde (UnB); Doutorando em Medicina Interna e Terapêutica (UNIFESP/ EPM); Docente e Coordenador de Pós-graduação no Centro Universitário de Brasília - UniCEUB; Fisioterapeuta do Centro de Reabilitação SPORTFISIO, no HOME e do Brasiliense Futebol Clube.

3 Membro Diretor da Sociedade Brasileira de Artroscopia e Traumatologia no Esporte (SBRATE) e Membro da Sociedade Brasileira de Cirurgia do Joelho (SBCJ) - Comitês da Sociedade Brasileira de Ortopedia e Traumatogia (SBOT); Fellow do Departamento de Cirurgia Ortopédica e Medicina Esportiva da Universidade de Pittsburgh; Diretor Médico do HOME - Hospital Ortopédico e Medicina Especializada, em Brasília/DF; Coordenador do Departamento Médico do Brasiliense Futebol Clube.

4 Fisioterapeuta da Clínica Reabilita. E-mail: rayanegeminiano@gmail.com.

5 Especialista em Fisioterapia Traumato-Ortopédica Funcional e Esportiva; Orientador de Prática em Ortopedia e Traumatologia no Centro Universitário de Brasília - UniCEUB; Fisioterapeuta do Centro de Reabilitação e Atividade Física REATIVA e do Brasiliense Futebol Clube.

6 Fisioterapeuta; Especialista em Piscina Terapêutica (UNICID) e nos Métodos Mckenzie, Mconell e GDS; Diretora do Centro Reabilitação SPORTFISIO, no HOME.

Fisioterapeuta; Especialista em Piscina Terapêutica (UNICID) e nos Métodos Mckenzie, Mconell e GDS; Diretora do Centro Reabilitação SPORTFISIO, no HOME.

\section{Resumo}

Lesões na articulação do joelho têm grande impacto na vida das pessoas devido à sua alta prevalência e sua repercussão clínica. Estudos comprovam a eficácia da cirurgia e do tratamento em curto prazo utilizando o tendão contralateral como enxerto. O presente estudo é do tipo transversal e tem como objetivo analisar a condição de pacientes que foram submetidos à cirurgia com enxerto contralateral e reabilitação do Ligamento Cruzado Anterior (LCA) após um período de 3 a 10 anos. Foram avaliados vinte e dois $(n=22)$ pacientes, selecionados aleatoriamente por meio de um banco de dados. Nos resultados encontrados, observou-se alteração apenas no Single Leg Hop Test (p-valor $=0,003$ ) e Pico de Torque (PT) de extensão a $60^{\circ} / \mathrm{s} \mathrm{e} 180^{\circ} / \mathrm{s}$ $(0,00$ e 0,04$)$. Nos parâmetros de estado clínico, os resultados obtidos foram benéficos. Portanto, o tratamento com o enxerto do tendão patelar contralateral apresentou bons resultados, visto que houve melhora da condição clínica esperada ao longo desses anos.

Palavras-chave: Análise clínica. Ligamento cruzado anterior. Tendão patelar. Tratamento.

\begin{abstract}
Injuries of the knee have a major impact on people's lives due to its high prevalence and its clinical consequences. Studies show the effectiveness of surgery and treatment for the short term using the contralateral tendon as a graft. This study is a cross-sectional and aims to analyze the condition of patients who underwent surgery with contralateral graft and rehabilitation after injury Anterior Cruciate Ligament (ACL) after a period of 3 to 10 years. We evaluated twenty-two $(n=22)$ patients, randomly selected through a database. In the results we observed changes only in Single Leg Hop Test $(\mathrm{p}$-value $=0.003)$ and PT extension at $60^{\circ} / \mathrm{s}$ and $180^{\circ} / \mathrm{s}(0.00$ to 0.04$)$. In the clinical parameters of the results obtained proved beneficial. Therefore, treatment with the contralateral patellar tendon graft had good results, since an improvement of clinical conditions expected over the years.
\end{abstract}

Keywords: Clinical analysis. Anterior cruciate ligament. Patellar tendon. Treatment. 


\section{Introdução}

O ligamento cruzado anterior (LCA) representa a contenção primária para a translação tibial anterior sobre o fêmur. Grood, Stowers e Noyes (1988) relataram que o LCA é responsável por $85 \%$ desse mecanismo entre $30^{\circ}$ a $90^{\circ}$ de flexão. Ressalte-se que as lesões desse ligamento têm sido objeto de estudo desde o século IX (JENSEN et al., 1983).

Segundo Feagin (1979), é uma das mais frequentes e debilitantes lesões do joelho. Nos Estados Unidos, a lesão do ligamento cruzado anterior acomete $60.000 \mathrm{a}$ 100.000 indivíduos por ano. No Brasil, não existem dados que demonstrem de forma clara a sua prevalência. Contudo, devido ao aumento da população interessada na prática de atividade física, essas lesões tendem a aumentar consideravelmente (ARNOLD; SHELBOURNE, 2000).

O tratamento das lesões do LCA deve levar em conta a idade, a atividade física praticada, suas pretensões nesse sentido e os aspectos particulares de cada indivíduo, podendo ser conservador ou cirúrgico. $\mathrm{O}$ tratamento conservador, de acordo com alguns estudos, apresenta um elevado índice de maus resultados (FEAGIN, 1985; HAWKINS; MISAMORE; MERRIT, 1986; FOWLER; REAGAN, 1987; CLANCY; RAY; ZOLTAN, 1988).

Segundo Feagin (1985), somente 10 a 30\% dos jovens podem viver bem sem o LCA, tendo sempre a sua atividade física direcionada para isso.

Ao utilizar o enxerto autógeno do tendão patelar e associá-lo a uma precoce reabilitação, bem orientada e com início no pré-operatório, observam-se resultados eficientes, desde que acompanhada da avaliação criteriosa que envolve parâmetros objetivos e subjetivos, como a avaliação do desempenho muscular (RUBINSTEIN et al., 1995; SHELBOURNE; DAVIS, 1999; SHELBOURNE; URCH, 2000; SHELBOURNE; VANADURONGWAN; GRAY, 2007).

No Brasil, Oliveira et al. (2006) e Lobo et al. (2006) demonstraram os resultados clínicos da recuperação em curto prazo de pacientes operados e reabilitados sob as mesmas condições e concluíram, consolidando o procedimento, utilizando o enxerto contralateral à lesão como sendo a primeira escolha na reconstrução do LCA.

De acordo com o contexto delineado, o problema que leva ao desenvolvimento desta pesquisa está carac- terizado pela necessidade de investigações no sentido de se obterem informações sobre o estado clínico após um período de 3 a 10 anos, considerado médio prazo, em indivíduos submetidos à cirurgia de reconstrução do LCA, utilizando-se enxerto do tendão patelar contralateral, a fim de corroborar a eficácia desse método de tratamento e verificar sua reprodutibilidade na população brasileira, visto que um menor prazo de recuperação, associado a outros parâmetros já evidenciados, será determinante para garantir um retorno seguro dos pacientes às suas atividades.

A pesquisa tem como objetivo avaliar a condição clínica em médio prazo dos joelhos doador e receptor de indivíduos submetidos à reabilitação após a cirurgia de reconstrução primária do LCA, utilizando enxerto do tendão patelar contralateral, além de verificar o nível de funcionalidade, a amplitude de movimento (ADM), a estabilidade articular e o desempenho muscular dos indivíduos, bem como analisar se há vantagem em obter um retorno precoce às atividades funcionais, por meio da condição em médio prazo.

\section{Materiais e métodos}

Foi realizado um estudo transversal com indivíduos submetidos à cirurgia de reconstrução do ligamento cruzado anterior e à reabilitação pré e pós-operatória.

Para obtenção dos sujeitos da pesquisa, foram selecionados aleatoriamente 24 pacientes, de acordo com a listagem de um banco de dados cedida pelo médico responsável pela cirurgia, porém 02 foram excluídos da pesquisa por não se enquadrarem nos critérios de inclusão, restando 22 participantes para compor o grupo de estudo. Todos foram atendidos na Clínica Integrada de Ortopedia e Reabilitação - CLINOR, localizada na Asa Norte, Brasília (DF), no período de janeiro de 2000 a dezembro de 2007, caracterizando uma evolução clínica em médio prazo ( 3 a 10 anos) e concordaram em participar da pesquisa assinando o Termo de Consentimento Livre e Esclarecido - TCLE aceito pelo comitê de ética da Universidade de Brasília - UnB (129/10) e reconhecido pelo comitê de ética do Centro Universitário de Brasília - UniCEUB (092/12).

Os critérios de inclusão foram: ter sofrido lesão traumática do LCA, sido submetido à cirurgia de recons- 
trução, utilizando enxerto do tendão contralateral pelo mesmo cirurgião e a um programa comum de reabilitação pré e pós-operatória descrito em vários trabalhos (SHELBOURNE; DAVIS, 1999; SHELBOURNE; URCH, 2000; SHELBOURNE; KLOTZ, 2006; SHELBOURNE; VANADURONGWAN; GRAY, 2007) no período de janeiro de 2000 a dezembro de 2007: ter idade compreendida entre 15 e 45 anos no período em que foi submetido ao tratamento clínico e cirúrgico, ser praticante de atividade física em nível recreacional e apresentar interesse em participar de todas as etapas do estudo. Os critérios de exclusão foram: apresentar histórico de outras lesões e/ou cirurgias nos joelhos ou associadas a eles, prévias ou posteriores à lesão do LCA, apresentar no momento da avaliação, dor e/ou edema nos joelhos, história de lesão muscular em quadríceps e/ou isquiotibiais e lesão do enxerto.

Para registro das informações de identificação dos sujeitos da pesquisa, bem como dos ajustes dos equipamentos e resultados das avaliações, foi elaborada uma Ficha de Avaliação do Joelho. Além disso, foi aplicado o Questionário de Lysholm que tem como objetivo pesquisar achados clínicos, sintomas e função do joelho.

Duas fisioterapeutas realizaram as avaliações em locais diferentes, uma no Hospital Ortopédico de Medicina Especializada - HOME e a outra na Universidade de Brasília - UnB. Os procedimentos foram realizados em dois dias de avaliação para finalizar a coleta dos dados necessários.

Para que houvesse descanso suficiente na pré-avaliação, os pacientes foram orientados a não realizar atividades físicas nas 24 horas que antecediam os testes e a comparecer ao local de coleta usando roupas de ginástica.

Durante a preparação dos indivíduos para os testes físicos, a pesquisadora responsável coletou as informações gerais, para verificação dos fatores de inclusão e exclusão na pesquisa e identificação das características individuais. O Questionário de Lysholm, um dos métodos utilizados, foi respondido sem a ajuda da avaliadora, que apenas esclareceu eventuais dúvidas sobre termos encontrados no texto. Em seguida, foram realizados testes manuais clínicos descritos por Moreira e Raimundo (2005): Lachman (paciente em decúbito dorsal com joelho flexionado a $30^{\circ}$ e pé apoiado, o examinador traciona a tíbia sobre o fêmur com as mãos), Pivot Shift (o paciente se posiciona em decúbito dorsal com o joelho em semifle- xão, o examinador rotaciona internamente a tíbia sobre o fêmur e aplica um leve esforço em valgo no joelho testado finalizando com a flexão) e Gavetas anterior e posterior (paciente em decúbito dorsal com joelho flexionado em $90^{\circ}$ e pé apoiado; o examinador segura com ambas as mãos o joelho e em seguida traciona a tíbia sobre o fêmur fixo). Todos os testes citados foram necessários para a análise de possível instabilidade ligamentar.

A avaliação da estabilidade articular foi o primeiro procedimento do exame físico dos pacientes. Realizada com auxílio da maca e por meio do KT- $1000^{\circ}$. Para interpretação dos achados artrométricos, foram considerados os valores de diferença entre os membros, considerando-se normais aqueles menores que $3 \mathrm{~mm}$ (LUSTOSA; FONSECA; ANDRADE, 2007).

A avaliação goniométrica foi realizada em seguida com auxílio do goniômetro CARCI", conforme o procedimento descrito por De Carlo e Sell (1997), no qual, para a avaliação da hiperextensão do joelho, o indivíduo foi posicionado em decúbito dorsal, membros inferiores elevados e com os calcanhares apoiados em um rolo para posicionamento, solicitando-se a ele o relaxamento completo dos membros para que a verificação fosse realizada de forma passiva. Para avaliar a flexão do joelho, o indivíduo foi posicionado em decúbito dorsal, com flexão do quadril a $90^{\circ}$ e flexão máxima do joelho de forma passiva. As avaliações da estabilidade articular e da amplitude de movimento foram realizadas pela mesma examinadora.

Para as coletas do peso e da estatura, foi utilizado o procedimento descrito por Monteiro (1998), com auxílio da balança digital LIDER e do estadiômetro SOEHNLE* O indivíduo, descalço, mantém-se na posição ortostática, com os pés unidos e voltados para frente, ombros relaxados e membros superiores ao longo do corpo. Para registro da estatura, solicitou-se ao indivíduo a realização de uma inspiração máxima, seguida de apneia, para então efetuar a leitura.

O Single Leg Hop Test foi realizado de acordo com o método descrito por De Carlo (1997). A trena antropométrica Sanny Medical foi fixada no chão e a extremidade anterior do pé dos pacientes foi posicionada sobre a primeira marcação para iniciar o teste. Eles foram orientados a saltar a maior distância possível com apenas uma perna de apoio e voltar ao chão com a mesma perna. Não houve restrição quanto ao uso dos membros superiores 
para auxiliar na impulsão. No momento da aterrissagem, os pacientes foram orientados a permanecer com o pé no local da queda e a distância entre o ponto posterior do calcanhar até a primeira marcação foi mensurada e considerada como a distância obtida no salto. Foram realizadas três tentativas em cada membro e a média das três coletas foi utilizada como o resultado principal.

A coleta de dados por meio do isocinético foi precedida de algumas etapas, como: aquecimento com auxílio da bicicleta ergométrica ERGO-FIT, alongamento e familiarização. Foi determinada a amplitude de movimento (ADM) de teste e o cálculo do peso do membro. Os movimentos realizados com o auxílio do dinamômetro isocinético Biodex System 3 Pro durante o teste foram: 5 repetições concêntricas máximas de quadríceps e isquiotibiais a velocidades de $60 \%$ s e $180 \%$ s. Durante a realização dos movimentos, os indivíduos foram encorajados a realizar força máxima a partir de estímulo verbal moderado do avaliador e feedback visual proporcionado pelo software do dinamômetro. Por fim, os candidatos tiveram o período pós-teste, com a finalidade de prevenir o aparecimento de sintomas adversos, realizando-se a aplicação de gelo, compressão e elevação por 20 minutos em ambos os joelhos, imediatamente após a realização do teste. Foram utilizados os valores obtidos de Pico de Torque a $60 \%$ s e $180 \%$ s (Peak Torque), que representa a força muscular máxima desenvolvida em qualquer posição da amplitude de movimento, obtido em Newton/ metro $(\mathrm{Nm})$.

Para análise radiográfica, foi utilizada a descrição de Kellgren e Lawrence (1957), onde os autores diferenciam a artrose em cinco graus de acordo com sinais radiográficos encontrados; a análise é feita utilizando-se os graus de 1 a 4 , sendo que 1 representa o início com um pequeno estreitamento no espaço articular presente no joelho, e 4 representa a visível perda do espaço articular acompanhada de deformidade do contorno ósseo, além da presença de osteófitos.

Todos os procedimentos da pesquisa foram realizados no setor de Fisioterapia do HOME, localizado na Asa Sul, Brasília (DF) e no Laboratório de Avaliação de Força no setor da Faculdade de Educação Física - FEF, da UnB, localizada na Asa Norte, Brasília DF, que continham os instrumentos necessários para a coleta dos dados. $\mathrm{O}$ diretor do hospital HOME e o responsável pela FEF auto- a assinatura da Declaração de Ciência Institucional e Termo de Responsabilidade.

A análise estatística foi realizada por meio do programa SPSS for Windows 17.0. Para testar a normalidade da variável em estudo, utilizou-se o Teste de Kolmogorov-Smirnov. Para a realização dos testes paramétricos ( $T$-student), foi adotando o nível de confiança de $95 \%$ e de significância 5\%, sendo que valores menores que 0.05 foram considerados estatisticamente significativos.

\section{Resultados}

A amostra selecionada para estudo foi composta por 22 indivíduos, com idade média e desvio padrão de $34,55 \pm 8,5$. Destes, 19 (86\%) eram do gênero masculino e 3 (14\%) do gênero feminino. Os valores médios e desvio padrão da estatura e peso foram respectivamente 1,75 \pm 0,09 e $85,06 \pm 16,35$ (Tabela 1).

Tabela 1 - Distribuição dos indivíduos do grupo de pesquisa. Médias e desvios padrão para estatura e peso.

\begin{tabular}{l|c}
\hline \multicolumn{1}{c|}{ Variáveis } & $\begin{array}{c}\text { Características do } \\
\text { Grupo de Pesquisa }\end{array}$ \\
\hline $\mathrm{N}^{\circ}$ de Indivíduos & 22 \\
Gênero Masculino & $19(86 \%)$ \\
Gênero Feminino & $3(14 \%)$ \\
Média de Idade & $34,55 \pm 8,5$ \\
Estatura & $1,75 \pm 0,09$ \\
Peso & $85,06 \pm 16,35$ \\
\hline
\end{tabular}

Todos os participantes praticavam esporte em nível recreacional, sendo que 13 deles $(59,09 \%)$ praticavam musculação, 07 (31,82\%) futebol, e 02 (9,09\%), tênis; os demais praticavam outra atividade adicional. De acordo com a Organização Mundial de Saúde - OMS, apresentaram IMC normal 7 (31,82\%), sobrepeso 11 (50\%) e obeso $4(18,18)$.

No exame radiológico, apenas 2 (9,09\%) indivíduos apresentaram grau 1 de artrose pela escala de Kellgren e Lawrence (1957), e os outros 20 (90,91\%) participantes apresentaram normalidade.

Os resultados do KT1000"' também não apresentaram alterações. A menor diferença entre os membros foi de $0,3 \mathrm{~mm}$ e a maior, de $2 \mathrm{~mm}$. A diferença média entre os indivíduos foi de $0,93 \mathrm{~mm}$.

Os testes realizados na coleta de dados como o Lackman, Pivot e Gaveta anterior e posterior apresenta- 
ram resultado negativo, ou seja, sem sinais de frouxidão ligamentar.

A amplitude articular do joelho para flexão e para hiperextensão pelo teste de goniometria apresentou valores normais de acordo com a Tabela 2.

Na Tabela 3, são observadas as medidas descritivas do Single Leg Hop Test, da Relação I/Q a 60\%/s, do Pico de Torque a $60 \%$ s (extensão e flexão), e Pico de Torque a180\% (extensão e flexão).
Observa-se, por meio da Tabela 4, normalidade entre os dados, pois o p-valor é maior que o nível de significância adotado ( $\mathrm{p}$-valor $>.05$ ). A normalidade foi testada entre a diferença (doador/receptor) dos dados por meio do Teste de Kolmogorov-Smirnov.

De acordo com os resultados, que seguiram uma distribuição normal, foi realizado o Teste Paramétrico T-Student (Pareado) para amostras dependentes (Tabela 5$)$.

Tabela 2 - Medidas descritivas do teste de goniometria.

\begin{tabular}{c|c|c|c|c|c|c}
\hline Variável & Movimento & Membro & Mín. & Máx. & Média & DP \\
\hline \multirow{3}{*}{$\begin{array}{c}\text { Goniometria } \\
\text { Passiva }\end{array}$} & \multirow{2}{*}{ Flexão } & Direito & $141^{\circ}$ & $150^{\circ}$ & $147,77^{\circ}$ & 3,22 \\
\cline { 2 - 7 } & \multirow{2}{*}{ Hiperextensão } & Esquerdo & $138^{\circ}$ & $150^{\circ}$ & $146,91^{\circ}$ & 3,64 \\
\cline { 3 - 7 } & & Direito & $2^{\circ}$ & $5^{\circ}$ & $4^{\circ}$ & 1,11 \\
\cline { 2 - 7 } & & Esquerdo & $4^{\circ}$ & $5^{\circ}$ & $4,36^{\circ}$ & 0,49 \\
\hline
\end{tabular}

Tabela 3 - Medidas descritivas do Single Leg Hop Test e do isocinético.

\begin{tabular}{|c|c|c|c|c|c|}
\hline Variáveis & Membro & Mínimo & Máximo & Média & DP \\
\hline \multirow{2}{*}{ Single Leg Hop Test } & Receptor & 1,19 & 2,07 & 1,66 & 0,26 \\
\hline & Doador & 1,18 & 2,35 & 1,76 & 0,33 \\
\hline \multirow{2}{*}{ Relação I/Q a 60\%/s } & Receptor & 41,80 & 70,00 & 53,19 & 7,51 \\
\hline & Doador & 45,90 & 71,30 & 56,25 & 6,84 \\
\hline \multirow{2}{*}{$\begin{array}{l}\text { Pico de Torque a } \\
60 \% \text { s Extensão }\end{array}$} & Receptor & 123,60 & 339,90 & 212,45 & 55,43 \\
\hline & Doador & 116,60 & 321,20 & 197,29 & 49,71 \\
\hline \multirow{2}{*}{$\begin{array}{c}\text { Pico de Torque a } \\
60 \% \text { s Flexão }\end{array}$} & Receptor & 55,80 & 150,80 & 111,05 & 24,48 \\
\hline & Doador & 67,90 & 149,80 & 110,38 & 23,95 \\
\hline \multirow{2}{*}{$\begin{array}{l}\text { Pico de Torque a } \\
180 \% \text { s Extensão }\end{array}$} & Receptor & 86,30 & 232,10 & 150,42 & 39,77 \\
\hline & Doador & 88,50 & 232,50 & 144,86 & 38,87 \\
\hline \multirow{2}{*}{$\begin{array}{c}\text { Pico de Torque a } \\
180 \% \text { s Flexão }\end{array}$} & Receptor & 40,40 & 147,70 & 90,29 & 24,45 \\
\hline & Doador & 45,60 & 139,50 & 87,06 & 23,52 \\
\hline
\end{tabular}

Tabela 4 - Teste de normalidade para doador e receptor.

\begin{tabular}{c|c}
\hline \multicolumn{1}{c|}{ Variáveis } & P-valor \\
\hline Single Leg Hop Test & 0,253 \\
\hline Relação I/Q à 60\%/s & 0,849 \\
\hline Pico de Torque a 60\%s - Extensão & 0,568 \\
\hline Pico de Torque a 60\% $/$ - Flexão & 0,901 \\
\hline Pico de Torque a 180\%s - Extensão & 0,847 \\
\hline Pico de Torque a $180 \%$ s - Flexão & 0,672 \\
\hline
\end{tabular}


Tabela 5 -Teste T-Student para Doador/Receptor. Brasília - DF, 2011.

\begin{tabular}{|c|c|c|c|c|c|c|c|c|}
\hline \multirow[t]{2}{*}{ Variáveis } & \multirow[t]{2}{*}{ Média } & \multirow[t]{2}{*}{$\begin{array}{l}\text { Desvio } \\
\text { Padrão }\end{array}$} & \multirow[t]{2}{*}{$\begin{array}{c}\text { Erro } \\
\text { Padrão }\end{array}$} & \multicolumn{2}{|c|}{$\begin{array}{c}\text { 95\% Intervalo de } \\
\text { Confiança das } \\
\text { Diferenças }\end{array}$} & \multirow[b]{2}{*}{$\mathrm{t}$} & \multirow[b]{2}{*}{ Gl } & \multirow[b]{2}{*}{$\mathrm{p}$-valor } \\
\hline & & & & Inferior & Superior & & & \\
\hline Single Leg Hop Test & $-0,10$ & 0,14 & 0,03 & $-0,17$ & $-0,04$ & $-3,34$ & 21 & 0,03 \\
\hline Relação I/Q a 60\%/s & $-3,06$ & 5,47 & 1,77 & $-5,48$ & $-0,63$ & $-2,62$ & 21 & 0,02 \\
\hline Relação I/Q a 180\%/s & $-0,04$ & 5,75 & 1,22 & $-2,59$ & 2,51 & $-0,03$ & 21 & 0,97 \\
\hline Pico de Torque de Extensão a $60 \% / s$ & 15,15 & 20,78 & 4,43 & 5,94 & 24,37 & 3,42 & 21 & 0,00 \\
\hline Pico de Torque de Extensão a $180 \%$ s & 5,56 & 11,62 & 2,48 & 0,41 & 10,71 & 2,24 & 21 & 0,04 \\
\hline Pico de Torque de Flexão a $60 \% / s$ & 0,66 & 8,27 & 1,76 & $-3,00$ & 4,33 & 0,38 & 21 & 0,71 \\
\hline Pico de Torque de Flexão a $180 \%$ s & 3,22 & 8,81 & 1,88 & $-0,68$ & 7,13 & 1,72 & 21 & 0,10 \\
\hline
\end{tabular}

Observa-se que há diferença entre receptor e doador, para o Single Leg Hop Test, para a Relação I/Q a 60\%, para o Pico de Torque de Extensão a 60\% e para o Pico de Torque de Extensão a 180\%. Como o p-valor = 0,003; 0,$02 ; 0,00$ e 0,04 , respectivamente.

Para o Questionário de Lysholm (Tabela 6), 8 voluntários apresentaram resultado "excelente", 11, "bom" e 3, "regular", sendo que os de resultado "regular" apontaram presença de dor após exercícios pesados e caminhadas longas. Os de resultado "bom" também apresentaram episódios ocasionais ou leves de dor após exercícios pesados e caminhadas longas.

Tabela 6 - Resultados do Questionário de Lysholm.

\section{Discussão}

Estudos demonstram que o LCA representa uma contenção muito importante para o complexo do joelho. Dessa forma e de acordo com os resultados obtidos na presente pesquisa, é possível estabelecer considerações importantes.

Os pacientes que fizeram parte do grupo de estudo realizaram cirurgia em um período entre 3 a 10 anos. Segundo Shelbourne, Vanadurongwan e Gray (2007), o período considerado como médio prazo está compreendido entre 2 e 10 anos após a cirurgia. Portanto, a pesquisa caracterizou-se no período considerado como médio prazo.
A faixa etária de maior incidência de lesões do LCA está compreendida entre 15 a 45 anos (SHELBOURNE; DAVIS, 1999). Dessa forma, a seleção da idade para este estudo foi delimitada nessa faixa etária.

Participaram da pesquisa tanto homens quanto mulheres, sendo que $19(86,36 \%)$ são do gênero masculino e somente $03(13,63 \%)$ são do gênero feminino. De acordo com os trabalhos de Beynnon et al. (2005) e César et al. (2008), as mulheres representam, de duas a oito vezes, maior propensão à ruptura do LCA que os homens quando participam de uma mesma prática esportiva. Os resultados foram positivos quando se comparou o gênero feminino com o gênero masculino. Isso foi possível levando-se em consideração a crescente inserção feminina no meio esportivo.

Aborda-se como ponto fraco do trabalho alguns critérios de exclusão que possivelmente diminuíram o índice de maus resultados. Na tentativa de direcionar o estudo à avaliação clínica, apenas de pacientes submetidos à cirurgia de reconstrução do ligamento cruzado anterior, excluíram-se os que apresentaram outras lesões ou cirurgias nos joelhos ou associadas a eles, prévias ou posteriores à lesão, lesão muscular em quadríceps e/ou isquiotibiais e lesão do enxerto. Pacientes que apresentaram dor e/ou edema nos joelhos também foram excluídos, devido à incapacidade de realizar os testes propostos, visto que tais pacientes poderiam representar resultados diferentes ao estudo.

Em relação ao quadro clínico dos pacientes avaliados na pesquisa constata-se que todos obtiveram exame clínico com bons resultados por meio dos testes realizados, como Lachman, Pivot Shift Test e Gavetas anterior e posterior que foram negativos. De acordo com o exame radiológico, a maioria dos resultados foi normal; 
$20(90,91 \%)$ apresentaram grau 0 de artrose e apenas 2 $(9,09 \%)$ indivíduos apresentaram grau 1 pela escala de Kellgren e Lawrence (1957). Além disso, todos os pacientes apresentaram IMC dentro da normalidade, o que representa um bom sinal de acordo com a OMS, visto que o sobrepeso é atualmente um risco para problemas ortopédicos, agindo tanto no surgimento quanto no agravamento do estado clínico.

Outro instrumento utilizado para avaliar os indivíduos do estudo, o KT-1000, representa uma forma eficiente para determinar a estabilidade do joelho e comprovar o resultado negativo obtido no exame clínico citado anteriormente. Ele é feito mediante do deslocamento do fêmur sobre a tíbia para verificação da lassidão ligamentar residual. É considerada normal uma discrepância de até $3 \mathrm{~mm}$ entre os membros sadio e lesionado (SHELBOURNE; THOMAS, 2005). A diferença média entre os participantes da pesquisa foi de $0,93 \mathrm{~mm}$.

Segundo o estudo de Abdalla et al. (2009), foi observada a precisão do diagnóstico do KT-1000 em pacientes que sofreram entorse de tornozelo, sendo que eles foram divididos em dois grupos, um que sofreu entorse em menos de quatro semanas e o outro que sofreu entorse em mais de quatro semanas. Após submeter os pacientes dos dois grupos ao procedimento, o estudo detectou lesão do LCA em todos os indivíduos. O autor observa que, utilizando o KT-1000, o diagnóstico de lesão do LCA foi preciso para ambos os grupos.

Um dos questionários validados que fornece para os pesquisadores um feedback em relação aos resultados obtidos com a cirurgia no joelho é o questionário de Lysholm. Na presente pesquisa observou-se que 50\% (11) dos pacientes caracterizava a cirurgia como boa, outros $36,36 \%$ (08), como excelente e $13,63 \%$ (03), como regular/razoável, de acordo com o questionário aplicado.

Petrou et al. (2006) acompanharam por 4 a 7 anos seus pacientes após a cirurgia. Utilizaram como um dos métodos avaliativos o Questionário de Lysholm e o artrômetro KT-1000. Dos participantes, 79\% retornaram às atividades normais 3 meses após a cirurgia. Pelo Questionário de Lysholm, 58\% obtiveram resultados excelentes, $34 \%$, bons, $8 \%$, razoáveis.

Observou-se em relação à goniometria que os valores obtidos estavam dentro da normalidade; no membro direito, $147,77^{\circ}$ de flexão e $4^{\circ}$ de hiperextensão, no membro esquerdo, $146,91^{\circ}$ de flexão e $4,36^{\circ}$ de hiperextensão. Havia simetria angular entre os membros, visto que nenhum indivíduo apresentou mais de $4^{\circ}$ de diferença. Além disso, comparando-se os graus obtidos na avaliação com os valores considerados normais, a amplitude de movimento dos avaliados após o período de médio prazo não apresentou diferença significativa.

O Pico de Torque (PT) e a relação isquiostibiais/ quadríceps (I/Q) foram avaliados por meio do teste isocinético. De acordo com o estudo de Shinzato et al. (1996) esse teste permite a sobrecarga do músculo em 100\% de sua capacidade máxima, em toda a ADM, tornando-o instrumento mais útil para avaliação da força muscular.

As velocidades utilizadas para o PT na pesquisa foram de $60 \%$ s e de $180 \%$, sendo que a primeira avalia o PT, por meio de uma velocidade angular lenta, e a segunda avalia a potência. Todos os valores são obtidos em Newton/metro (Nm) (SHELBOURNE; VANADURONGWAN; GRAY, 2007).

Na presente pesquisa houve diferença significativa entre receptor e doador para $\mathrm{PT}$ a $60 \%$ de extensão e PT a $180^{\circ} / \mathrm{s}$ de extensão, sendo os valores $\mathrm{p}=0,00$ e $\mathrm{p}=0,04$ respectivamente, adotando um nível de significância de 0,05 . Porém, não houve diferença significativa entre o PT a $60 \%$ de flexão $(\mathrm{p}=0,71)$ e PT a $180 \%$ s de flexão $(\mathrm{p}=0,10)$. Dessa forma, observa-se que os músculos flexores se recuperam mais rápido sem que haja uma diferença importante entre os membros. Já em relação os membros direito e esquerdo, não houve diferença significativa dos dados.

De acordo com Alves et al. (2009), a lesão do ligamento cruzado anterior acarreta fraqueza muscular, principalmente no músculo quadríceps femoral, responsável pela extensão do joelho. Também pode ocorrer a falta de propriocepção no membro lesionado, gerando uma inibição das unidades motoras afetando também o membro não acometido.

De acordo com Abdalla et al. (2009), é importante entender o porquê do déficit de força muscular de quadríceps que se observa em pacientes que fizeram cirurgia de reconstrução do LCA, utilizando como enxerto o tendão patelar contralateral. No estudo foram analisados os resultados obtidos por meio do exame isocinético e da artrometria para os tendões flexores e tendão patelar, em que 63 pacientes foram divididos em dois grupos, um com 30 pacientes que utilizaram o tendão patelar, e o ou- 
tro com 33 pacientes que utilizaram os tendões flexores. Os resultados mostram que não houve diferença na artrometria entre os grupos. Já no isocinético, observou-se que o grupo que utilizou tendão patelar apresentou maior pico de torque de flexão e maior déficit de extensão; já o grupo dos flexores possui maior déficit de flexão.

As pessoas possuem joelhos simétricos e, quando ocorre uma lesão em um dos joelhos, ele é deixado de lado para as atividades normais, tais como andar, agachar e subir e descer escadas. O problema evolui para a perda de movimento e força no membro lesionado, gerando assimetria. Para o retorno às atividades esportivas, é necessário que, além da ausência de sinais inflamatórios, haja simetria de ADM e desempenho muscular entre os membros, que permitirão o restabelecimento da funcionalidade (JOHNSON, 1993).

Shelbourne e Klotz (2006) revisaram os resultados de 19 anos de cirurgia do LCA, com uma média de 250 reconstruções por ano. O objetivo foi demonstrar o que havia aprendido com sua experiência clínica. $\mathrm{O}$ estudo concluiu que a reconstrução do LCA contralateral trouxe melhores resultados, com menor tempo de recuperação. Atribui-se a essa nova perspectiva a possibilidade dos pacientes se tornarem mais simétricos.

Em relação ao Single Leg Hop Test, houve diminuição da propriocepção $(\mathrm{p}=0,003)$ em relação aos dados para receptor e doador. Esse resultado ocorre devido à diminuição de força muscular em quadríceps e a inibição das unidades motoras.

Bonfim et al. (2009) analisaram a propriocepção de indivíduos que recorreram à reconstrução do LCA com enxerto autólogo e homólogo com o joelho contralateral normal. O estudo observou que existe uma redução significativa na propriocepção dos joelhos operados quando comparados com o joelho não operado.

Os indivíduos estudados na pesquisa apresentaram comprometimento no pico de torque da força extensora a $60 \%$ do membro doador e na relação I/Q a $60 \%$ (p-0,02); contudo, essa alteração não foi suficientemente significativa na velocidade de contração, além de não apresentar alteração da relação I/Q a 180\%/s (p-0,97).

Em pacientes com lesão do LCA, nota-se aumento dos valores da relação I/Q devido ao aumento da atividade reflexa dos isquiostibiais e a instabilidade gerada pela perda ligamentar (WALLA et al., 1985; SOLOMONOW et al., 1987).

Segundo Shelbourne e Urch (2000), quando existem bons resultados em relação aos ganhos de amplitude de movimento, força muscular e propriocepção, pode-se atribuir ao tratamento fisioterapêutico iniciado precocemente, com a reabilitação ocorrendo de forma simultânea, porém diferenciada para ambos os joelhos, adquirindo melhores ganhos funcionais.

\section{Conclusão}

Com base na análise do estudo obtido e comparando com os achados encontrados na literatura, pode-se concluir que a condição clínica dos pacientes, após um período de médio prazo, é satisfatória. Observa-se uma diminuição de força muscular em quadríceps superior a força perdida de isquiostibiais, porém esse dado não altera o excelente nível de funcionalidade dos participantes da pesquisa. É importante ressaltar que os critérios de exclusão influenciaram os resultados positivos da pesquisa, porém foi inevitável essa seleção a fim de proteger o paciente de uma possível lesão. Conclui-se que, após a cirurgia de reconstrução do LCA utilizando o enxerto do tendão patelar contralateral, é possível obter um retorno precoce às atividades funcionais sem prejuízo no quadro clínico pós-operatório.

\section{Referências}

ABDALLA, R. J. et al. Comparação entre os resultados obtidos na reconstrução do ligamento cruzado anterior do joelho utilizando dois tipos de enxertos autólogos: tendão patelar versus semitendíneo e grácil. Revista Brasileira de Ortopedia, São Paulo, v. 44, n. 3, p. 204-207, maio/jun. 2009. doi: 10.1590/S0102-36162009000300005

ALVES, P. H. M. et al. Lesão do ligamento cruzado anterior e atrofia do músculo quadríceps femoral. Bioscience Journal, Uberlândia, v. 25, n. 1, p. 146-156, jan./fev. 2009.

ARNOLD, T.; SHELBOURNE, K. D. A perioperative rehabilitation program for anterior cruciate ligament surgery. The Physician and Sports Medicine, Minneapolis, v. 28, n. 1, p. 31-44, jan. 2000. doi: 10.3810/ psm.2000.01.621

BEYNNON, B. D. et al. The effect of estradiol and progesterone on knee and ankle joint laxity. The American Journal of Sports Medicine, Baltimore, v. 33, n. 9, p. 
1298-1304, sep. 2005. doi:10.1177/0363546505275149

BIODEX Medical Systems Inc. Manual de aplicações/ operações. Nova York: Biodex Medical Systems, 1998.

CÉSAR, G. M.; PEREIRA, V. S.; SERRÃO, F. V. Influência dos hormônios sexuais na frouxidão e lesão do lca: revisão bibliográfica. Fisioterapia em Movimento, Curitiba, v. 21, n. 3, p. 93-100, jul./set. 2008.

CLANCY, W. G.; RAY, M.; ZOLTAN, D. J. Acute tears of the anterior cruciate ligament: surgical versus conservative treatment. The Journal of Bone \& Joint Surgery, Boston, v. 70, n. 10, p. 1483-1488, dec. 1988.

DE CARLO, M. S.; SELL, K. E. Normative data for range of motion and single-leg hop in high school athletes. Journal of Sport Rehabilitation, United States, v. 6, n. 3, p. 246-255, aug. 1997.

DE CARLO, M.; SHELBOURNE, K.; ONEACRE, K. Rehabilitation program for both knees when contralateral autogenous patellar tendon graft is used for primary anterior cruciate ligament reconstruction: A case study. Journal of Orthopaedic \& Sports Physical Therapy, Washington, v. 29, n. 3, p. 144-159, mar. 1999.

FEAGIN, J. A. The syndrome of the torn anterior cruciate ligament. Orthopedic Clinics of North America, Philadelphia, v. 10, n. 1, p. 81-90, jan. 1979.

FEAGIN, J. A.; LAMBERT, K. L. Mechanism of injury and pathology of anterior cruciate ligament injuries. Orthopedic Clinics of North America, Philadelphia, v. 16, n. 1, p. 41-45, jan. 1985.

FOWLER, P.; REGAN, W. The patient with symptomatic chronic anterior cruciate ligament insufficiency. Results of minimal arthroscopic surgery and rehabilitation. The American Journal of Sports Medicine, Baltimore, v. 15, n. 4, p. 321-325, jul. 1987. doi:10.1177/036354658701500405

GROOD, E.; STOWERS, S.; NOYES, F. Limits of movement in the human knee: Effect of sectioning the posterior cruciate ligament and posterolateral structures. Journal of Bone \& Joint Surgery, Boston, v. 70, n. 1, p. 88-97, jan. 1988.

HAWKINS, R.; MISAMORE, G.; MERRIT, T. Followup of the acute nonoperated isolated anterior cruciate ligament tear. The American Journal of Sports Medicine, Baltimore, v. 14, n. 3, p. 205-210, jun. 1986. doi: $10.1177 / 036354658601400305$

JENSEN, J. et al. Reconstruction procedures for anterior cruciate ligament insufficiency: a computer analysis of clinical results. The American Journal of Sports
Medicine, Baltimore, v. 11, n. 4, p. 240-248, jul. 1983. doi: $10.1177 / 036354658301100411$

JOHNSON, D. L. Acute knee injuries: an introduction. Clinics in Sports Medicine, Philadelphia, v. 12, n. 2, p. 344, apr. 1993.

KELLGREN, J. H.; LAWRENCE, J. S. Radiological assessment of osteo-arthrosis. Annals of the Rheumatic Diseases, London, v. 16, n. 4, p. 494-502, dec. 1957.

LOBO, P. et al. Resultados clínico/funcionais pósreconstrução primária do ligamento cruzado anterior com tendão patelar contralateral. Seguimento de 02 anos. In: CONGRESSO BRASILEIRO DE ARTROSCOPIA, 11., 2006, Salvador. Anais... Salvador, 2006.

LUSTOSA, L. P.; FONSECA, S. T.; ANDRADE, M. A. P. Reconstrução do ligamento cruzado anterior: impacto do desempenho muscular e funcional no retorno ao mesmo nível de atividade pré-lesão. Acta Ortopédica Brasileira, São Paulo, v. 15, n. 5, p. 280-284, 2007.

MOREIRA, D.; RAIMUNDO, A. K. S. Guia prático de testes especiais do aparelho locomotor. Brasilia: Thesaurus, 2005.

MONTEIRO, W. Personal Training: manual para avaliação e prescrição de condicionamento físico. Rio de Janeiro: Sprint, 1998.

OLIVEIRA, M. et al. Programa de Reabilitação de Ambos os Joelhos Após a Cirurgia Primária de Reconstrução do LCA Utilizando Enxerto Autógeno de Ligamento Patelar Contralateral. In: CONGRESSO BRASILEIRO DE ARTROSCOPIA, 11., 2006, Salvador. Anais... Salvador, 2006.

PETROU G. et al. Reconstruction of the anterior cruciate ligament using the polyester $\mathrm{ABC}$ ligament scaffold: a minimum follow-up of four years. Journal of Bone \& Joint Surgery, London, v. 88B, n. 7, p. 893-899, jul. 2006. doi: 10.1302/0301-620X.88B7.17671

RUBINSTEIN, R. et al. Effect on knee stability in full hyperextension is restored immediately after autogenous bone-patellar-bone anterior cruciate ligament reconstruction. The American Journal of Sports Medicine, Baltimore, v. 23, n. 3, p. 365-368, jun. 1995. doi: $10.1177 / 036354659502300321$

SHELBOURNE, K.; VANADURONGWAN, B.; GRAY, T. Primary anterior cruciate ligament reconstruction using contralateral patellar tendon autograft. Clinics in Sports Medicine, Philadelphia, v. 26, n. 4, p. 549-565, oct. 2007. doi: 10.1016/j.csm.2007.06.008

SHELBOURNE, K.; DAVIS, T. Evaluation of knee stability before and after participation in a functional 
sports agility program during rehabilitation after anterior cruciate ligament reconstruction. The American Journal of Sports Medicine, Baltimore, v. 27, n. 2, p. 156-161, mar. 1999.

SHELBOURNE, K.; URCH, S. Primary anterior cruciate ligament reconstruction using the contralateral autogenous patellar tendon graft. The American Journal of Sports Medicine, Baltimore, v. 28, n. 5, p. 651-658, sep. 2000 .

SHELBOURNE, K.; THOMAS, J. A. Contralateral patellar tendon and the Shelbourne experience: part 2 - results of revision anterior cruciate ligament reconstruction. Sports Medicine and Arthroscopy Review, New York, v. 13, n. 2, p. 69-72, jun. 2005.

SHELBOURNE, K. D.; KLOTZ, C. What I have learned about the ACL: utilizing a progressive rehabilitation scheme to achieve total knee symmetry after anterior cruciate ligament reconstrution. Journal of Orthopaedic Science, Tokyo, v. 11, n. 3, p. 318-325, may 2006. doi: 10.1007/s00776-006-1007-z

SHINZATO, G. T. et al. Protocolo de avaliação funcional de joelho em patologias ortopédicas. Acta Fisiátrica, São Paulo, v. 3, n. 1, p. 30-36, jan. 1996.

SOLOMONOW, $M$. et al. The synergistic action of the anterior cruciate ligament and thigh muscles in maintaining joint stability. The American Journal of Sports and Medicine, Baltimore, v. 15, n. 3, p. 207-213, jun. 1987. doi: 10.1177/036354658701500302

WALLA, D. J. et al. Hamstring control and the unstable anterior cruciate ligament-deficient knee. The American Journal of Sports Medicine, Baltimore, v. 13, n. 1, p. 3439, jan. 1985. doi: 10.1177/036354658501300106 